\section{BRAZIULIAN JOURNAL \\ OF MEDICAL AND BIOLOGICAL RLSF.ARCH}

www.bjournal.com.br
ISSN 0100-879X

Volume 43 (03) 226-324 March 2010

BIOMEDICAL SCIENCES

AND

CLINICAL INVESTIGATION

Braz J Med Biol Res, March 2010, Volume 43(3) 316-323

Hypomagnesemia is a risk factor for nonrecovery of renal function and mortality in AIDS patients with acute kidney injury

M.S. Biagioni Santos, A.C. Seguro and L. Andrade

The Brazilian Journal of Medical and Biological Research is partially financed by
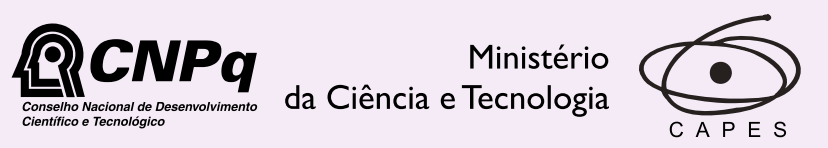

Ministério da Educação

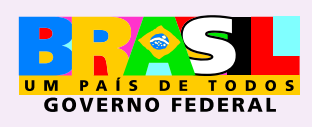

DFAPESP

Institutional Sponsors 


\title{
Hypomagnesemia is a risk factor for nonrecovery of renal function and mortality in AIDS patients with acute kidney injury
}

\author{
M.S. Biagioni Santos ${ }^{1}$, A.C. Seguro ${ }^{1,2}$ and L. Andrade ${ }^{1,2}$ \\ 1 Instituto de Infectologia Emílio Ribas, São Paulo, SP, Brasil \\ ${ }^{2}$ Disciplina de Nefrologia, Faculdade de Medicina, Universidade de São Paulo, São Paulo, SP, Brasil
}

\begin{abstract}
The objective of the present study was to determine the prevalence of electrolyte disturbances in AIDS patients developing acute kidney injury in the hospital setting, as well as to determine whether such disturbances constitute a risk factor for nephrotoxic and ischemic injury. A prospective, observational cohort study was carried out. Hospitalized AIDS patients were evaluated for age; gender; coinfection with hepatitis; diabetes mellitus; hypertension; time since HIV seroconversion; CD4 count; HIV viral load; proteinuria; serum levels of creatinine, urea, sodium, potassium and magnesium; antiretroviral use; nephrotoxic drug use; sepsis; intensive care unit (ICU) admission, and the need for dialysis. Each of these characteristics was correlated with the development of acute kidney injury, with recovery of renal function and with survival. Fifty-four patients developed acute kidney injury: $72 \%$ were males, $59 \%$ had been HIV-infected for $>5$ years, $72 \%$ had CD 4 counts $<200$ cells $/ \mathrm{mm}^{3}$, $87 \%$ developed electrolyte disturbances, 33\% recovered renal function, and 56\% survived. ICU admission, dialysis, sepsis and hypomagnesemia were all significantly associated with nonrecovery of renal function and with mortality. Nonrecovery of renal function was significantly associated with hypomagnesemia, as was mortality in the multivariate analysis. The risks for nonrecovery of renal function and for death were 6.94 and 6.92 times greater, respectively, for patients with hypomagnesemia. In hospitalized AIDS patients, hypomagnesemia is a risk factor for nonrecovery of renal function and for in-hospital mortality. To determine whether hypomagnesemia is a determinant or simply a marker of critical illness, further studies involving magnesium supplementation in AIDS patients are warranted.
\end{abstract}

Key words: Acquired immunodeficiency syndrome; Acute kidney failure; Water-electrolyte imbalance; Magnesium deficiency; Drug toxicity

\section{Introduction}

It is recognized that renal complications have a substantive impact on the course of AIDS and alter the prognosis of the disease $(1,2)$. In patients with AIDS, kidney disease can occur as a primary manifestation of HIV infection, as a secondary complication of an underlying illness or due to the side effects of antiretroviral therapy $(3,4)$. Kidney disease has emerged as a leading cause of death among AIDS patients in the era of highly active antiretroviral therapy (HAART) (5).

Acute kidney injury (AKI) is one of the most common causes of renal failure in AIDS patients (6), as well as a strong predictor of in-hospital morbidity and mortality in the general population (7). Patients with AIDS frequently require hospitalization and are often treated with drug combinations, factors that contribute to the development of AKI (1), which has been reported to occur in up to $20 \%$ of hospitalized
AIDS patients (8). Acute tubular necrosis (ATN) is the most common cause of $\mathrm{AKI}$ in hospitalized patients. The risk of AKI related to volume depletion, hemodynamic stress, nephrotoxic medications, or the administration of contrast medium is greater among patients hospitalized with complications of AIDS (4). Sepsis is considered to be the leading cause of ischemicAKI in AIDS patients. In such patients, impaired renal handling of water and sodium also causes volume depletion (9). In hospitalized AIDS patients, AKI resulting from druginduced ATN is common. Antiretroviral drug use can cause renal failure through a variety of mechanisms: direct renal tubular toxicity (ATN, Fanconi-like syndrome, distal tubular acidosis, etc.), obstructions (crystal deposition in the kidney), and glomerular lesions $(10,11)$. Other potential causes of $\mathrm{AKI}$ in AIDS patients include thrombotic microangiopathy

Correspondence: L. Andrade, Laboratório de Pesquisa Básica, FM, USP, Av. Dr. Arnaldo, 455, Sala 3310, 01246-903 São Paulo, SP, Brasil. Fax: +55-11-3088-2267. E-mail: luciacan@usp.br

Received August 18, 2009. Accepted January 7, 2010. Available online January 22, 2010. Published March $12,2010$. 
and opportunistic infections of the renal parenchyma (12). Patients with AIDS who develop AKI can also present underlying diseases such as HIV-associated nephropathy and other glomerular diseases (13), as well as non-HIV-related kidney diseases such as diabetes and hypertension, as well as hepatitis C- or B-related nephropathy (14).

Electrolyte disturbances are common in AIDS patients (15). Marked changes in electrolyte balance can result from the many and varied drugs used to control AIDS infection or can be secondary to opportunistic infections.

It has been shown that hypokalemia constitutes a risk factor for the development of AKI $(16,17)$. Hypokalemia also causes a marked increase in gentamicin nephrotoxicity (18). In addition, hypokalemia is a common complication of treatment with amphotericin $B$ and potentiates amphotericin B nephrotoxicity $(19,20)$. The antiretroviral drugs zidovudine (AZT) and didanosine (ddl) are widely used in AIDS patients, and data suggest that their use in patients with hypokalemia can have adverse effects on renal function (21). It has been shown that both drugs decrease glomerular filtration rate and renal blood flow in hypokalemic rats, but that only AZT reduces glomerular filtration rate and renal blood flow in rats with hypomagnesemia. Therefore, chronic AZT and ddl administration can produce AKI in AIDS patients with hypokalemia or hypomagnesemia (21). Seguro et al. (17) showed that hypokalemia also enhances the tubular damage resulting from ischemic injury. In addition, magnesium supplementation has been shown to protect against postischemic AKI (22).

Although hypomagnesemia is also a common disturbance in AIDS patients, its effects in such patients have not been studied thoroughly.

The aim of the present study was to determine the prevalence of electrolyte disturbances in AIDS patients who develop AKI in the hospital setting, as well as whether such disturbances constitute a risk factor for nephrotoxic and ischemic injury. We also evaluated the recovery of renal function and mortality rates in this population of patients.

\section{Material and Methods}

\section{Study design and population}

This was a prospective cohort study conducted at the Emílio Ribas Institute of Infectology in São Paulo, Brazil. All hospitalized AIDS patients over 18 years of age were eligible for inclusion. Those developing AKI between May and August of 2006 were selected for study. Patients presenting serum creatinine levels $<1.5 \mathrm{mg} / \mathrm{dL}$ were excluded, as were pregnant patients and those with pre-existing chronic renal disease. Clinical, biochemical and demographic data were collected at enrollment and prospectively. The study design was approved by the Ethics in Research Committee of the Emílio Ribas Institute of Infectology and written informed consent was obtained from all patients, who participated in the study.

\section{Data collection}

Data related to the following variables were collected: gender, age, coinfection with hepatitis $B$, coinfection with hepatitis $\mathrm{C}$, diabetes mellitus, hypertension, interval between HIV seroconversion and the occurrence of AKI, use of antiretroviral therapy, nephrotoxic drugs administered in the hospital, sepsis, and dehydration. Laboratory testing included the following parameters: CD4 count, HIV viral load, serum levels of urea, creatinine, sodium, potassium and magnesium, urinary protein excretion, and urinalysis.

\section{Outcome measures}

Each patient was evaluated prospectively throughout the entire hospital stay. The primary outcome measures were survival, duration of AKI, need for renal replacement therapy, and admission to the intensive care unit (ICU).

\section{Comorbidities and laboratory data}

Underlying clinical conditions and laboratory test results at the time of $\mathrm{AKI}$ development were reviewed in order to determine the potential cause of AKI.

A diagnosis of $A K I$ was made if serum creatinine levels remained $\geq 1.5 \mathrm{mg} / \mathrm{dL}$ for more than 3 consecutive days during the hospital stay. Patients presenting serum creatinine levels $\geq 1.5 \mathrm{mg} / \mathrm{dL}$ for less than 3 days were considered to have prerenal azotemia and were excluded from the analysis. The criteria for not to consider prerenal azotemia after 3 days were based on the clinical analysis of the nephrologist (all patients were evaluated by the same nephrologist). The clinical signs of salt depletion were analyzed: postural hypotension, reduction in central venous pressure and skin turgor. Also, we did not consider prerenal azotemia if saline infusion was given for the extracellular volume expansion and the serum levels of creatinine remained the same or even increased despite the treatment. Recovery of renal function was defined as a return of serum creatinine levels to $<1.5 \mathrm{mg} / \mathrm{dL}$.

Coinfection with hepatitis B was defined as serum positivity for hepatitis B surface antigen or hepatitis Be antigen. Coinfection with hepatitis $C$ was defined as serum positivity for hepatitis $C$ antibodies or detectable hepatitis $C$ virus RNA.

Diabetes mellitus was defined as glucose intolerance requiring dietary or pharmacologic management. Patients under treatment with antihypertensive medications at the time of admission were classified as hypertensive. Hyponatremia was defined as serum sodium levels $<135 \mathrm{mEq} / \mathrm{L}$, whereas serum sodium levels $>145 \mathrm{mEq} / \mathrm{L}$ were considered to be indicative of hypernatremia. Hyperkalemia was defined as serum potassium levels $>5 \mathrm{mEq} / \mathrm{L}$, and hypokalemia was defined as serum potassium levels $<3.5 \mathrm{mEq} / \mathrm{L}$. Hypomagnesemia was defined as serum magnesium levels $<1.7 \mathrm{mg} / \mathrm{dL}$, and hypermagnesemia was defined as serum magnesium levels $>2.1 \mathrm{mg} / \mathrm{dL}$.

HIV RNA levels were quantified by the reverse tran- 
scriptase polymerase chain reaction using the standard and ultrasensitive versions of the Amplicor HIV Monitor Assay (Roche Diagnostics, USA).

\section{Statistical analysis}

Statistical analysis was based on the frequency of nonrecovery of renal function and on the mortality rate, as well as on the odds ratios estimated using univariate and multivariate logistic regression. In the univariate analysis, factors associated with nonrecovery and mortality were analyzed individually. The initial multivariate model included all variables that presented an association of $P \leq 0.15$ in the univariate analysis. In the final model, only variables that maintained an association of $P \leq 0.10$ were retained, and we employed a Wald statistic backward stepwise selection. The statistical analysis was performed using the Statistical Package for the Social Sciences, version 14.0, for Windows (SPSS Inc., USA).

\section{Results}

Clinical, biochemical and demographic characteristics

Of the 54 patients selected for inclusion, 15 were females and 39 were males. Most of the patients (59\%) had been HIV-infected for at least 5 years, and $72 \%$ presented CD4 counts $<200$ cells $/ \mathrm{mm}^{3}$. Table 1 shows the general characteristics of the cohort.

Forty-seven patients (87\%) presented at least one electrolyte disturbance, principally hyponatremia (in 32 patients, 59\%), followed by hypokalemia (in 23 patients, $46 \%$ ) and hypomagnesemia (in 18 patients, 33\%). The mean ( \pm SEM) serum level of magnesium was $1.76 \pm 0.06$ $\mathrm{mg} / \mathrm{dL}$ (range: $1.1-2.6 \mathrm{mg} / \mathrm{dL}$ ). Proteinuria was measured in only $28(52 \%)$ of the 54 patients evaluated. Among these 28 patients, proteinuria was higher than $1 \mathrm{~g} /$ day in 18 (64\%).

Thirty-five patients $(65 \%)$ were under treatment with at least one nephrotoxic drug, primarily vancomycin, amphotericin, tenofovir, angiotensin-converting enzyme inhibitors, ganciclovir, foscarnet, or indinavir. Intravenous contrast medium was used in 30 (56\%) of the 54 patients.

The principal causes of renal failure were sepsis (in $48 \%$ ), dehydration (in 32\%) and treatment with nephrotoxic drugs (in 65\%). Underlying conditions included hypertension (in 30\%), diabetes (in 9\%) and congestive heart failure (in $4 \%$ ). Nephrotic syndrome was identified in 8 patients $(15 \%)$.

\section{Outcomes}

Unlike what is seen in the general population, only 18 patients $(33 \%)$ recovered renal function.

There were 21 patients (39\%) who required dialysis. It is of note that only $2(10 \%)$ of these 21 patients recovered renal function, whereas $13(62 \%)$ died in the hospital. Of the 33 patients $(61 \%)$ who did not require dialysis, $16(49 \%)$ recovered renal function and $11(33 \%)$ died in the hospital.
Table 1. Clinical features of the 54 AIDS patients who developed acute kidney injury in the hospital.

\begin{tabular}{|c|c|}
\hline Characteristic & $\mathrm{N}(\%)$ \\
\hline \multicolumn{2}{|l|}{ Gender } \\
\hline Male & $39(72 \%)$ \\
\hline Female & $15(28 \%)$ \\
\hline \multicolumn{2}{|l|}{ Age (years) } \\
\hline $18-39$ & $25(46 \%)$ \\
\hline $40-60$ & $27(50 \%)$ \\
\hline$>60$ & $2(4 \%)$ \\
\hline \multicolumn{2}{|c|}{ Time since HIV seroconversion } \\
\hline$<1$ year & $13(24 \%)$ \\
\hline $1-5$ years & $8(15 \%)$ \\
\hline$>5$ years & $32(59 \%)$ \\
\hline Unknown & $1(2 \%)$ \\
\hline \multicolumn{2}{|l|}{ HAART } \\
\hline Yes & $18(33 \%)$ \\
\hline No & $36(67 \%)$ \\
\hline \multicolumn{2}{|c|}{ Illicit intravenous drug use } \\
\hline Yes & $8(15 \%)$ \\
\hline No & $33(61 \%)$ \\
\hline Unknown & $13(24 \%)$ \\
\hline \multicolumn{2}{|l|}{ Hypertension } \\
\hline Yes & $16(30 \%)$ \\
\hline No & $38(70 \%)$ \\
\hline \multicolumn{2}{|l|}{ Diabetes } \\
\hline Yes & $5(9 \%)$ \\
\hline No & $49(91 \%)$ \\
\hline \multicolumn{2}{|c|}{ Hepatitis B coinfection } \\
\hline Yes & $3(6 \%)$ \\
\hline No & $36(72 \%)$ \\
\hline Unknown & $12(22 \%)$ \\
\hline \multicolumn{2}{|c|}{ Hepatitis C coinfection } \\
\hline Yes & $12(22 \%)$ \\
\hline No & $30(56 \%)$ \\
\hline Unknown & $12(22 \%)$ \\
\hline \multicolumn{2}{|c|}{ CD4 count (cells $/ \mathrm{mm}^{3}$ ) } \\
\hline$\geq 200$ & $8(15 \%)$ \\
\hline$<200$ & $39(72 \%)$ \\
\hline Unknown & $7(13 \%)$ \\
\hline
\end{tabular}

HAART = highly active antiretroviral therapy.

In terms of mortality, the difference between AIDS patients who recovered renal function and those who did not was significant $(P<0.001)$.

Of the cohort as a whole, 28 patients $(52 \%)$ were admitted to the ICU, and $18(64 \%)$ of them died in the hospital. Of the 26 patients (48\%) who were not admitted to the ICU, only $6(23 \%)$ died in the hospital. The overall in-hospital mortality rate was $44 \%$. 


\section{Risk factors for nonrecovery of renal function}

Failure to recover renal function did not correlate significantly with gender ( $P$ $>0.999)$, age $(P=0.127)$, diabetes $(P$ $=0.741)$, coinfection with hepatitis $B(P$ $=0.929)$, coinfection with hepatitis $C(P$ $=0.364)$, HAART use $(P=0.541)$, CD4 count $(P=0.264)$, proteinuria $>3 \mathrm{~g} /$ day $(P=0.185)$, hyponatremia $(P=0.271)$, or hypokalemia $(P=0.488)$. Using univariate analysis (Table 2), we found that the nonrecovery of renal function correlated significantly with ICU admission $(P=0.004)$, the need for dialysis $(P=0.008)$, sepsis $(P=0.010)$, dehydration $(P=0.010)$, and hypomagnesemia $(P=0.020)$.

In the multivariate logistic regression analysis (Table 3 ), the independent risk factors for nonrecovery of renal function were hypomagnesemia $(P=0.03)$ and ICU admission $(P=0.082)$. The risk for nonrecovery of renal function was 3.8 times greater in patients admitted to the ICU than in those who did not require intensive care $(P=0.02)$. Interestingly, hypomagnesemia was also a risk factor for the nonrecovery of renal function. Of the 23 patients who presented serum magnesium levels $\geq 1.7$ $\mathrm{mg} / \mathrm{dL}, 11$ (48\%) recovered renal function. However, of the 18 patients who presented serum magnesium levels $<1.7 \mathrm{mg} / \mathrm{dL}$, only $2(11 \%)$ recovered renal function $(P$ $=0.030)$. The risk for the nonrecovery of renal function was 6.9 times greater in patients with hypomagnesemia than in those without.

\section{Risk factors for mortality}

No significant correlation was found in the univariate analysis (Table 4) between mortality and the following variables: age $(P$ $=0.626)$, gender $(P=0.839), C D 4$ count $(P$ $=0.232)$, HAART use $(P=0.087)$, coinfection with hepatitis $B(P=0.731)$, coinfection with hepatitis $C(P=0.921)$, diabetes $(P=$ $0.274)$, proteinuria $>3 \mathrm{~g} /$ day $(P=0.124)$, hypokalemia $(P=0.569)$, and hyponatremia $(P=0.529)$. However, we could demonstrate that mortality correlated significantly with the following variables: ICU admission $(P=0.003)$, requiring dialysis $(P=0.043)$, sepsis $(P<0.001)$, and hypomagnesemia $(P=0.013)$.

Mortality was quite high $(64 \%)$
Table 2. Univariate analysis of nonrecovery of renal function in relation to sociodemographic and clinical characteristics.

\begin{tabular}{|c|c|c|c|c|}
\hline Characteristic & Recovery & Nonrecovery & OR $(95 \% \mathrm{Cl})$ & $\mathrm{P}$ \\
\hline \multicolumn{5}{|l|}{ Age group } \\
\hline$<40$ years & $11(44 \%)$ & $14(56 \%)$ & 1.000 & \\
\hline$\geq 40$ years & $7(24 \%)$ & $22(76 \%)$ & $2.469(0.774-7.882)$ & 0.127 \\
\hline \multicolumn{5}{|l|}{ Gender } \\
\hline Male & $13(33 \%)$ & $26(67 \%)$ & 1.000 & \\
\hline Female & $5(33 \%)$ & $10(67 \%)$ & $1.000(0.283-3.537)$ & 1.000 \\
\hline \multicolumn{5}{|l|}{ Hypertension } \\
\hline No & $13(34 \%)$ & $25(66 \%)$ & 1.000 & \\
\hline Yes & $5(31 \%)$ & $11(69 \%)$ & $1.144(0.327-4.000)$ & 0.833 \\
\hline \multicolumn{5}{|l|}{ Diabetes } \\
\hline No & $16(33 \%)$ & $33(67 \%)$ & 1.000 & \\
\hline Yes & $2(40 \%)$ & $3(60 \%)$ & $0.727(0.110-4.796)$ & 0.741 \\
\hline \multicolumn{5}{|l|}{ Hepatitis B } \\
\hline No & $14(37 \%)$ & $25(64 \%)$ & 1.000 & \\
\hline Yes & $1(33 \%)$ & $2(67 \%)$ & $1.120(0.093-13.482)$ & 0.929 \\
\hline \multicolumn{5}{|l|}{ Hepatitis C } \\
\hline No & $12(40 \%)$ & $18(60 \%)$ & 1.000 & \\
\hline Yes & $3(25 \%)$ & $9(75 \%)$ & $2.000(0.448-8.936)$ & 0.364 \\
\hline \multicolumn{5}{|c|}{ Time since HIV seroconversion } \\
\hline$<1$ year & $1(8 \%)$ & $12(92 \%)$ & 1.000 & \\
\hline $1-5$ years & $5(46 \%)$ & $6(55 \%)$ & $0.100(0.009-1.059)$ & 0.056 \\
\hline$>5$ years & $12(41 \%)$ & $17(59 \%)$ & $0.118(0.013-1.034)$ & 0.054 \\
\hline \multicolumn{5}{|l|}{ HAART } \\
\hline No & $13(36 \%)$ & $23(64 \%)$ & 1.000 & \\
\hline Yes & $5(28 \%)$ & $13(72 \%)$ & $1.470(0.427-5.055)$ & 0.541 \\
\hline \multicolumn{5}{|l|}{ CD4 (cells $/ \mathrm{mm}^{3}$ ) } \\
\hline$\geq 200$ & $1(13 \%)$ & $7(88 \%)$ & 1.000 & \\
\hline$<200$ & $13(33 \%)$ & $26(67 \%)$ & $0.286(0.032-2.575)$ & 0.264 \\
\hline \multicolumn{5}{|c|}{ Viral load (copies $/ \mathrm{mL}$ ) } \\
\hline$<400$ & $1(20 \%)$ & $4(80 \%)$ & 1.000 & \\
\hline $400-100,000$ & $3(30 \%)$ & $7(70 \%)$ & $0.583(0.044-7$ & 0.682 \\
\hline$>100,000$ & $7(47 \%)$ & $8(53 \%)$ & $0.286(0.026-3.196)$ & 0.309 \\
\hline \multicolumn{5}{|c|}{ Nephrotic syndrome } \\
\hline No & $8(40 \%)$ & $12(60 \%)$ & 1.000 & \\
\hline Yes & $1(13 \%)$ & $7(88 \%)$ & $4.667(0.478-45.546)$ & 0.185 \\
\hline \multicolumn{5}{|l|}{ Radiocontrast } \\
\hline No & $9(36 \%)$ & $16(64 \%)$ & 1.000 & \\
\hline Yes & $9(31 \%)$ & $20(69 \%)$ & $1.250(0.402-3.885)$ & 0.700 \\
\hline \multicolumn{5}{|l|}{ Need for dialysis } \\
\hline No & $16(49 \%)$ & $17(52 \%)$ & 1.000 & \\
\hline Yes & $2(10 \%)$ & $19(91 \%)$ & $8.941(1.789-44.688)$ & 0.008 \\
\hline \multicolumn{5}{|l|}{ ICU admission } \\
\hline No & $14(54 \%)$ & $12(46 \%)$ & 1.000 & \\
\hline Yes & $4(14 \%)$ & $24(86 \%)$ & $7.000(1.890-25.932)$ & 0.004 \\
\hline \multicolumn{5}{|l|}{ Hyponatremia } \\
\hline No & $9(43 \%)$ & $12(57 \%)$ & 1.000 & \\
\hline Yes & $9(28 \%)$ & $23(72 \%)$ & $1.917(0.602-6.101)$ & 0.271 \\
\hline Hypokalemia & & & & \\
\hline No & $9(30 \%)$ & $21(70 \%)$ & 1.000 & \\
\hline Yes & $9(39 \%)$ & $14(61 \%)$ & $0.667(0.212-2.095)$ & 0.488 \\
\hline Hypomagnesem & & & & \\
\hline No & $11(48 \%)$ & $12(52 \%)$ & 1.000 & \\
\hline Yes & $2(11 \%)$ & $16(89 \%)$ & $7.333(1.364-39.438)$ & 0.020 \\
\hline Dehydration & & & & \\
\hline No & $8(22 \%)$ & $29(78 \%)$ & 1.000 & \\
\hline Yes & $10(59 \%)$ & $7(41 \%)$ & $0.193(0.056-0.669)$ & 0.010 \\
\hline Sepsis & & & & \\
\hline No & $14(50 \%)$ & $14(50 \%)$ & 1.000 & \\
\hline Yes & $4(15 \%)$ & $22(85 \%)$ & $5.500(1.503-20.133)$ & 0.010 \\
\hline Nephrotoxic dru & & & & \\
\hline No & $7(39 \%)$ & $11(61 \%)$ & 1.000 & \\
\hline Yes & $10(29 \%)$ & $25(71 \%)$ & $1.591(0.480-5.273)$ & 0.448 \\
\hline
\end{tabular}

$\mathrm{OR}=$ odds ratio estimated by univariate logistic regression; HAART = highly active antiretroviral therapy; ICU = intensive care unit. For each variable: $\mathrm{OR}=1.000$ indicates the reference category. For certain variables, the total number of patients is less than 54 due to missing data. 
Table 3. Final results of the multivariate analysis of sociodemographic and clinical characteristics associated with nonrecovery of renal function.

\begin{tabular}{lcccc}
\hline Characteristic & Beta \pm SEM & Wald test (d.f. =1) & OR $(95 \% \mathrm{Cl})$ & P \\
\hline $\begin{array}{l}\text { ICU admission } \\
\quad \text { No }\end{array}$ & 0 & & & \\
$\quad$ Yes & $1.354 \pm 0.778$ & 3.026 & $3.874(0.842-17.811)$ & 0.082 \\
Hypomagnesemia & & & & \\
$\quad$ No & 0 & & 1.000 & \\
$\quad$ Yes & $1.938 \pm 0.893$ & 4.713 & $6.945(1.207-39.958)$ & 0.030 \\
Constant & $-0.548 \pm 0.567$ & 0.934 & - & 0.334 \\
\hline
\end{tabular}

d.f. = degrees of freedom; OR = odds ratio estimated by multivariate logistic regression; $\mathrm{ICU}=$ intensive care unit. For each variable: $\mathrm{OR}=1.000$ indicates the reference category. In addition to these variables, the initial multivariate model included age, time since HIV seroconversion, need for dialysis, electrolyte disturbances, dehydration, and sepsis.

among the patients admitted to the ICU.

In multiple logistic regression analysis (Table 5), the independent risk factors for mortality were hypomagnesemia $(P=0.033)$ and sepsis $(P=0.003)$.

The most interesting finding in the present study was the correlation between hypomagnesemia and mortality $(P=0.033)$. Of the 18 patients who presented hypomagnesemia, $11(62 \%)$ died in the hospital, compared with only $5(22 \%)$ of the 23 patients presenting normal serum levels of magnesium. We found that the risk of death for patients presenting serum magnesium levels $<1.7 \mathrm{mg} / \mathrm{dL}$ was 6.92 times greater than that for those presenting serum magnesium levels $\geq 1.7 \mathrm{mg} / \mathrm{dL}$.

\section{Discussion}

The results of the present study emphasize the variety of clinical causes of AKI in hospitalized AIDS patients, the use of multiple nephrotoxic drugs for these patients and the impact that electrolyte disturbances have on the course of the disease.

Our study population was predominantly male. The majority of the patients evaluated had been HIV-infected for at least 5 years, presented low CD4 counts and were not receiving regular antiretroviral therapy. Noncompliance with treatment continues to be a challenge in the treatment of these patients.

Our findings are compatible with those of many other studies in which renal dysfunction has been shown to occur predominantly in the more advanced stages of HIV infection $(14,15)$. Sepsis is considered to be a major cause of AKI in AIDS patients $(5,6,9)$. In a sample of patients with advanced HIV infection, approximately half of those presenting AKI also had sepsis, which causes prerenal azotemia by promoting systemic vasodilation and arterial hypotension (6). Sepsis was the leading cause of renal failure in our study population as well.
Sixty-five percent of the patients presenting AKI were receiving potentially nephrotoxic drugs, contrast medium being the most common. Contrast-induced AKI continues to be a leading cause of hospital-acquired renal failure (23). Various studies have demonstrated that diabetic nephropathy, volume depletion, dehydration, hypercholesterolemia, and preexisting renal insufficiency are the most important risk factors for the development of contrast-induced AKI (23).

There are no data on whether AIDS can predispose to contrast-induced AKI. However, AIDS patients are typically under treatment with other potentially nephrotoxic drugs, as well as having sepsis, presenting a high risk for volume depletion (due to dehydration and diarrhea) and being frequently submitted to imaging studies involving the administration of contrast medium.

In view of these facts, it is not surprising that contrast medium was the most common potentially nephrotoxic drug employed in our cohort, and that vancomycin was the second most common. It should be borne in mind that vancomycin is used only in patients with severe infections, which might explain the fact that a significant correlation between vancomycin use and mortality, as well as between vancomycin use and nonrecovery of renal function, was found only in the univariate analysis.

In the present study, hyponatremia was the most common electrolyte disturbance. Hyponatremia occurs in 36$56 \%$ of hospitalized AIDS patients and typically indicates inappropriate arginine vasopressin secretion or volume depletion secondary to gastrointestinal fluid loss $(15,24)$.

The second most common electrolyte disturbance detected in our study population was hypokalemia, which, since it can be caused by drugs such as gentamicin, amphotericin $B$, acyclovir, and tenofovir, is frequently observed in AIDS patients $(18,20,25,26)$. In addition, the clinical symptoms of AIDS (diarrhea, malnutrition and anorexia) predispose to hypokalemia. It is also known that hypokalemia enhances the tubular damage resulting from ischemic injury (16). 
Table 4. Univariate analysis of mortality in relation to sociodemographic and clinical characteristics.

\begin{tabular}{|c|c|c|c|c|}
\hline Characteristic & Survival & Death & OR $(95 \% \mathrm{Cl})$ & $\mathrm{P}$ \\
\hline \multicolumn{5}{|l|}{ Age group } \\
\hline$<40$ years & $13(52 \%)$ & $12(48 \%)$ & 1.000 & \\
\hline$\geq 40$ years & $17(59 \%)$ & $12(41 \%)$ & $0.765(0.260-2.247)$ & 0.626 \\
\hline \multicolumn{5}{|l|}{ Gender } \\
\hline Male & $22(56 \%)$ & $17(44 \%)$ & 1.000 & \\
\hline Female & $8(53 \%)$ & $7(47 \%)$ & $1.132(0.343-3.743)$ & 0.839 \\
\hline \multicolumn{5}{|l|}{ Hypertension } \\
\hline No & $19(50 \%)$ & $19(50 \%)$ & 1.000 & \\
\hline Yes & $11(69 \%)$ & $5(31 \%)$ & $0.455(0.132-1.561)$ & 0.210 \\
\hline \multicolumn{5}{|l|}{ Diabetes } \\
\hline No & $26(53 \%)$ & $23(47 \%)$ & 1.000 & \\
\hline Yes & $4(80 \%)$ & $1(20 \%)$ & $0.283(0.029-2.714)$ & 0.274 \\
\hline \multicolumn{5}{|l|}{ Hepatitis B } \\
\hline No & $22(56 \%)$ & $17(44 \%)$ & 1.000 & \\
\hline Yes & $2(67 \%)$ & $1(33 \%)$ & $0.647(0.054-7.746)$ & 0.731 \\
\hline \multicolumn{5}{|l|}{ Hepatitis C } \\
\hline No & $17(57 \%)$ & $13(43 \%)$ & 1.000 & \\
\hline Yes & $7(58 \%)$ & $5(42 \%)$ & $0.934(0.241-3.625)$ & 0.921 \\
\hline \multicolumn{5}{|c|}{ Time since HIV seroconversion } \\
\hline$<1$ year & $3(23 \%)$ & $10(77 \%)$ & 1.000 & \\
\hline $1-5$ years & $6(55 \%)$ & $5(46 \%)$ & $0.250(0.043-1.443)$ & 0.121 \\
\hline$>5$ years & $21(72 \%)$ & $8(28 \%)$ & $0.114(0.025-0.526)$ & 0.005 \\
\hline \multicolumn{5}{|l|}{ HAART } \\
\hline No & $17(47 \%)$ & $19(53 \%)$ & 1.000 & \\
\hline Yes & $13(72 \%)$ & $5(28 \%)$ & $0.344(0.101-1.167)$ & 0.087 \\
\hline \multicolumn{5}{|l|}{ CD4 (cells $\left./ \mathrm{mm}^{3}\right)$} \\
\hline$\geq 200$ & $6(75 \%)$ & $2(25 \%)$ & 1.000 & \\
\hline$<200$ & $20(51 \%)$ & $19(49 \%)$ & $2.850(0.511-15.901)$ & 0.232 \\
\hline \multicolumn{5}{|c|}{ Viral load (copies/mL) } \\
\hline$<400$ & $4(80 \%)$ & $1(20 \%)$ & 1.000 & \\
\hline $400-100,000$ & $6(60 \%)$ & $4(40 \%)$ & $2.667(0.212-33.486)$ & 0.447 \\
\hline$>100,000$ & $8(53 \%)$ & $7(47 \%)$ & $3.500(0.313-39.153)$ & 0.309 \\
\hline \multicolumn{5}{|c|}{ Nephrotic syndrome } \\
\hline No & $16(80 \%)$ & $4(20 \%)$ & 1.000 & \\
\hline Yes & $4(50 \%)$ & $4(50 \%)$ & $4.000(0.684-23.406)$ & 0.124 \\
\hline \multicolumn{5}{|l|}{ Radiocontrast } \\
\hline No & $16(64 \%)$ & $9(36 \%)$ & 1.000 & \\
\hline Yes & $14(48 \%)$ & $15(52 \%)$ & $1.905(0.638-5.689)$ & 0.248 \\
\hline \multicolumn{5}{|l|}{ Need for dialysis } \\
\hline No & $22(67 \%)$ & $11(33 \%)$ & 1.000 & \\
\hline Yes & $8(38 \%)$ & $13(62 \%)$ & $3.250(1.039-10.162)$ & 0.043 \\
\hline \multicolumn{5}{|l|}{ ICU admission } \\
\hline No & $20(77 \%)$ & $6(23 \%)$ & 1.000 & \\
\hline Yes & $10(36 \%)$ & $18(64 \%)$ & $6.000(1.815-19.837)$ & 0.003 \\
\hline \multicolumn{5}{|l|}{ Hyponatremia } \\
\hline No & $13(62 \%)$ & $8(38 \%)$ & 1.000 & \\
\hline Yes & $17(53 \%)$ & $15(47 \%)$ & $1.434(0.467-4.401)$ & 0.529 \\
\hline Hypokalemia & & & & \\
\hline No & $18(60 \%)$ & $12(40 \%)$ & 1.000 & \\
\hline Yes & $12(52 \%)$ & $11(48 \%)$ & $1.375(0.459-4.117)$ & 0.569 \\
\hline Hypomagnesem & & & & \\
\hline No & $18(78 \%)$ & $5(22 \%)$ & 1.000 & \\
\hline Yes & $7(39 \%)$ & $11(61 \%)$ & $5.657(1.436-22.286)$ & 0.013 \\
\hline Dehydration & & & & \\
\hline No & $19(51 \%)$ & $18(49 \%)$ & 1.000 & \\
\hline Yes & $11(65 \%)$ & $6(35 \%)$ & $0.576(0.176-1.884)$ & 0.361 \\
\hline Sepsis & & & & \\
\hline No & $24(86 \%)$ & $4(14 \%)$ & 1.000 & \\
\hline Yes & $6(23 \%)$ & $20(77 \%)$ & $20.000(4.945-80.894)$ & 0.000 \\
\hline Nephrotoxic dru & & & & \\
\hline No & $11(61 \%)$ & $7(39 \%)$ & 1.000 & \\
\hline Yes & $18(51 \%)$ & $17(49 \%)$ & $1.484(0.467-4.718)$ & 0.503 \\
\hline
\end{tabular}

$\mathrm{OR}=$ odds ratio estimated by univariate logistic regression; HAART = highly active antiretroviral therapy; ICU = intensive care unit. For each variable: $\mathrm{OR}=1.000$ indicates the reference category. For certain variables, the total number of patients is less than 54 due to missing data.
In contrast to what would be expected, hypokalemia did not correlate with the nonrecovery of renal function in the present study.

Hypomagnesemia is a common entity, occurring in up to $12 \%$ of hospitalized patients (27). The incidence can be as high as $65 \%$ in patients in intensive care settings, in which nutrition, diuretics, hypoalbuminemia, and aminoglycosides can play important roles $(27,28)$. Gastrointestinal losses, renal losses (due to volume expansion, as well as to the use of pentamidine, amphotericin and diuretic drugs), redistribution and hypokalemia are all potential causes of hypomagnesemia $(27,28)$.

Hypomagnesemia is considered to be a common electrolyte disturbance in patients with AIDS (15). Since AIDS patients commonly present diarrhea and malnutrition and are treated with drugs that can cause magnesium loss, they are at high risk for developing hypomagnesemia, which reportedly occurs in approximately $29 \%$ of such patients (15). Magnesium plays a basic role in various organ functions, and the kidney is the main regulator of magnesium $(27,28)$. In mammals, the magnesium ion plays an important role, since the intracellular level of free magnesium regulates intermediary metabolism, DNA/RNAstructure, DNA/RNA synthesis, cell growth, cell reproduction, membrane structure, potassium transport, calcium ion transport, signal transduction modulation, fat synthesis, and protein synthesis (27-29). Since the adenosine triphosphate-magnesium complex is bound and then hydrolyzed by enzymes, magnesium is a cofactor for most adenosine triphosphates $(28,29)$.

It has been shown that hypomagnesemia is a risk factor for AKI (22). de Araujo et al. (22) demonstrated that AZT induces a decrease in glomerular filtration rate and in renal blood flow in rats with hypomagnesemia. Hypomagnesemia also predisposes to AZT nephrotoxicity (21). Therefore, chronic administration of AZT can produce AKI in AIDS patients with hypomagnesemia. de Araujo et al. (22) also showed that magnesium supplementation protects against postischemic AKI. These investigators found that renal blood flow in ischemic rats receiving magnesium supplementation is comparable to that observed in 
Table 5. Final results of the multivariate analysis of sociodemographic and clinical characteristics associated with mortality.

\begin{tabular}{lcccc}
\hline Characteristic & Beta \pm SEM & Wald test (d.f. =1) & OR $(95 \% \mathrm{Cl})$ & $\mathrm{P}$ \\
\hline $\begin{array}{l}\text { Hypomagnesemia } \\
\text { No }\end{array}$ & 0 & & & \\
$\quad$ Yes & $1.935 \pm 0.905$ & 4.569 & $6.923(1.174-40.807)$ & 0.033 \\
Sepsis & 0 & & & \\
No & & & 1.000 & \\
Yes & $2.762 \pm 0.919$ & 9.041 & $15.827(2.616-95.774)$ & 0.003 \\
Constant & $-2.873 \pm 0.909$ & 9.994 & - & 0.002 \\
\hline
\end{tabular}

d.f. = degrees of freedom; $\mathrm{OR}=$ odds ratio estimated by multivariate logistic regression. For each variable: $O R=1.000$ indicates the reference category. In addition to these variables, the initial multivariate model included time since HIV seroconversion, highly active antiretroviral therapy, nephrotic syndrome, need for dialysis, electrolyte disturbances, dehydration, and sepsis.

nonischemic rats. It is known that hypomagnesemia leads to hypertension, atherogenesis and stroke, although the mechanisms involved remain ill-defined (30).

It has also been shown that patients with hypertension, ischemic heart disease or stroke exhibit significant magnesium depletion (31). Recent in vitro studies of aortic and cerebrovascular smooth muscle cells from humans, rats and dogs have demonstrated that reductions in serum magnesium levels to below those considered normal induce the expression of at least two proto-oncogenes (c-fos and c-jun), as well as of the nuclear factor-kappa B (NF-kB) transcription factor (30). Since it is known that mRNA expression of c-fos, $\mathrm{c}$-jun and NF-KB increases after renal ischemia/reperfusion, these factors might also be involved in the pro-inflammatory and oxidative renal processes (32). Renal ischemia-induced hypomagnesemia might be associated with up-regulation of proto-oncogenes and of $\mathrm{NF}-\mathrm{kB}$. In various cells, including peripheral blood mononuclear cells, magnesium is involved in myriad reactions and functions: enzymatic reactions, operation of channel, receptor and intracellular signaling molecules, as well as nucleic acid and protein conformation $(27,33)$. Here, we have demonstrated for the first time that hypomagnesemia is a risk factor for mortality and for nonrecovery of renal function in AIDS patients.

\section{References}

1. Franceschini N, Napravnik S, Eron JJ Jr, Szczech LA, Finn WF. Incidence and etiology of acute renal failure among ambulatory HIV-infected patients. Kidney Int 2005; 67: $1526-$ 1531.

2. D'Agati V, Appel GB. HIV infection and the kidney. J Am Soc Nephrol 1997; 8: 138-152.

3. Balow JE. Nephropathy in the context of HIV infection. Kidney Int 2005; 67: 1632-1633.

4. Dellow EL, Unwin RJ, Miller RF. Presentation, diagnosis, and
The relationship between hypomagnesemia and mortality has been well described. Rubeiz et al. (34) reported that mortality rates were nearly twice as high in hypomagnesemic patients as in patients presenting normal serum levels of magnesium. Soliman et al. (35) demonstrated that developing ionized hypomagnesemia during an ICU stay correlated with a poor prognosis. However, there are no available reports showing that magnesium supplementation can improve mortality in hypomagnesemic patients in the ICU setting. In animal models, magnesium deficiency has been shown to increase production of inflammatory cytokines (36).

As previously stated, sepsis was the leading cause of AKI in our study population. Salem et al. (37) showed that progressive magnesium deficiency and hypomagnesemia are strongly associated with increased mortality in experimental sepsis. In patients with sepsis or septic shock, the prevalence of hypomagnesemia is high, and sepsis has been identified as an independent risk factor for developing hypomagnesemia during an ICU stay (35). Moreover, studies have suggested that low magnesium concentration may contribute to the pathogenesis of coronary atherosclerosis or acute thrombosis (38).

In order to classify the severity of AKI in hospitalized patients, we used the definition of AKI established by the Adult AIDS Clinical Trial Groups (39). This might constitute a limitation of the study, since it is possible that, by using this definition, we missed some cases of $\mathrm{AKI}$ in which there were smaller increases in serum creatinine.

In conclusion, hypomagnesemia in hospitalized AIDS patients is a risk factor for nonrecovery of renal function and for in-hospital mortality. Studies involving magnesium supplementation in AIDS patients are warranted in order to ascertain whether hypomagnesemia is a determinant or simply a marker of critical illness. 
1578-1585.

7. Chertow GM, Soroko SH, Paganini EP, Cho KC, Himmelfarb J, Ikizler TA, et al. Mortality after acute renal failure: models for prognostic stratification and risk adjustment. Kidney Int 2006; 70: 1120-1126.

8. Sandhu JS, Singla K, Sandhu P. HIV associated renal disease. J Indian Acad Clim Med 2004; 5: 331-334.

9. Perazella MA. Acute renal failure in HIV-infected patients: a brief review of common causes. Am J Med Sci 2000; 319: 385-391.

10. Izzedine H, Launay-Vacher V, Deray G. Antiviral drug-induced nephrotoxicity. Am J Kidney Dis 2005; 45: 804-817.

11. Daugas E, Rougier JP, Hill G. HAART-related nephropathies in HIV-infected patients. Kidney Int 2005; 67: 393-403.

12. Kimmel PL, Barisoni L, Kopp JB. Pathogenesis and treatment of HIV-associated renal diseases: lessons from clinical and animal studies, molecular pathologic correlations, and genetic investigations. Ann Intern Med 2003; 139: 214226.

13. Szczech LA. Renal diseases associated with human immunodeficiency virus infection: epidemiology, clinical course, and management. Clin Infect Dis 2001; 33: 115-119.

14. Weiner NJ, Goodman JW, Kimmel PL. The HIV-associated renal diseases: current insight into pathogenesis and treatment. Kidney Int 2003; 63: 1618-1631.

15. Wyatt CM, Winston J. Renal disease in patients with HIV. Curr Infect Dis Rep 2006; 8: 76-81.

16. Menahem SA, Perry GJ, Dowling J, Thomson NM. Hypokalaemia-induced acute renal failure. Nephrol Dial Transplant 1999; 14: 2216-2218.

17. Seguro AC, Shimizu MH, Monteiro JL, Rocha AS. Effect of potassium depletion on ischemic renal failure. Nephron 1989; 51: 350-354.

18. Goodhart GL, Handelsman S. Gentamicin and hypokalemia. Ann Intern Med 1985; 103: 645-646.

19. Bernardo JF, Murakami S, Branch RA, Sabra R. Potassium depletion potentiates amphotericin-B-induced toxicity to renal tubules. Nephron 1995; 70: 235-241.

20. Sabra R, Branch RA. Amphotericin B nephrotoxicity. Drug Saf 1990; 5: 94-108.

21. Seguro AC, de Araujo M, Seguro FS, Rienzo M, Magaldi AJ, Campos SB. Effects of hypokalemia and hypomagnesemia on zidovudine (AZT) and didanosine (ddl) nephrotoxicity in rats. Clin Nephrol 2003; 59: 267-272.

22. de Araujo M, Andrade L, Coimbra TM, Rodrigues AC Jr, Seguro AC. Magnesium supplementation combined with $\mathrm{N}$-acetylcysteine protects against postischemic acute renal failure. J Am Soc Nephrol 2005; 16: 3339-3349.

23. Marenzi G, Bartorelli AL. Recent advances in the prevention of radiocontrast-induced nephropathy. Curr Opin Crit Care 2004; 10: 505-509.

24. Upadhyay A, Jaber BL, Madias NE. Incidence and preva- lence of hyponatremia. Am J Med 2006; 119: S30-S35.

25. Andrade L, Reboucas NA, Seguro AC. Down-regulation of $\mathrm{Na}^{+}$transporters and AQP2 is responsible for acyclovirinduced polyuria and hypophosphatemia. Kidney Int 2004; 65: 175-183.

26. Libório AB, Andrade L, Pereira LV, Sanches TR, Shimizu $\mathrm{MH}$, Seguro AC. Rosiglitazone reverses tenofovir-induced nephrotoxicity. Kidney Int 2008; 74: 910-918.

27. Agus ZS. Hypomagnesemia. J Am Soc Nephrol 1999; 10: 1616-1622.

28. Fawcett WJ, Haxby EJ, Male DA. Magnesium: physiology and pharmacology. Br J Anaesth 1999; 83: 302-320.

29. Altura BM, Altura BT. Magnesium and cardiovascular biology: an important link between cardiovascular risk factors and atherogenesis. Cell Mol Biol Res 1995; 41: 347-359.

30. Altura BM, Kostellow AB, Zhang A, Li W, Morrill GA, Gupta $\mathrm{RK}$, et al. Expression of the nuclear factor-kappaB and proto-oncogenes c-fos and c-jun are induced by low extracellular $\mathrm{Mg}^{2+}$ in aortic and cerebral vascular smooth muscle cells: possible links to hypertension, atherogenesis, and stroke. Am J Hypertens 2003; 16: 701-707.

31. Altura BM, Altura BT, Gebrewold A, Ising H, Gunther T. Magnesium deficiency and hypertension: correlation between magnesium-deficient diets and microcirculatory changes in situ. Science 1984; 223: 1315-1317.

32. Safirstein R, Price PM, Saggi SJ, Harris RC. Changes in gene expression after temporary renal ischemia. Kidney Int 1990; 37: 1515-1521.

33. Shechter M, Sharir M, Labrador MJ, Forrester J, Silver B, Bairey Merz CN. Oral magnesium therapy improves endothelial function in patients with coronary artery disease. Circulation 2000; 102: 2353-2358.

34. Rubeiz GJ, Thill-Baharozian M, Hardie D, Carlson RW. Association of hypomagnesemia and mortality in acutely ill medical patients. Crit Care Med 1993; 21: 203-209.

35. Soliman HM, Mercan D, Lobo SS, Melot C, Vincent JL. Development of ionized hypomagnesemia is associated with higher mortality rates. Crit Care Med 2003; 31: 1082-1087.

36. Malpuech-Brugere C, Nowacki W, Daveau M, Gueux E, Linard $\mathrm{C}$, Rock E, et al. Inflammatory response following acute magnesium deficiency in the rat. Biochim Biophys Acta 2000; 1501: 91-98.

37. Salem M, Kasinski N, Munoz R, Chernow B. Progressive magnesium deficiency increases mortality from endotoxin challenge: protective effects of acute magnesium replacement therapy. Crit Care Med 1995; 23: 108-118.

38. Liao F, Folsom AR, Brancati FL. Is low magnesium concentration a risk factor for coronary heart disease? The Atherosclerosis Risk in Communities (ARIC) Study. Am Heart $J$ 1998; 136: 480-490.

39. Schrier RW, Wang W. Acute renal failure and sepsis. N Engl J Med 2004; 351: 159-169. 